\title{
A IGREJA CATÓLICA EM APARECIDA-SP: UM AGENTE SOCIAL NA PRODUÇÃO E REPRODUÇÃO DO ESPAÇO URBANO
}

\section{The Catholic Church in "Aparecida-SP": a social agent in the production and reproduction of urban space}

Ivo Francisco Barbosa

Mestre em Geografia, Professor do Município de Aparecida - SP

ivo_francisco@hotmail.com

Artigo recebido em 09/06/2016 e aceito em 14/10/2016

DOI: $10.12957 /$ tamoios.2016.23228

\begin{abstract}
Resumo: Sabe-se que sua condição turístico-religiosa é comumente conhecida, no entanto, o próprio processo de produção e reprodução desse espaço urbano na atualidade e de sua formação decorrem de outras análises, sobretudo, das ações de diversos agentes sociais. Assim, esse processo é proveniente dessas relações sociais, mormente, da contextualização das relações sociais históricas com a região do Vale do Paraíba, com o município de Guaratinguetá e, principalmente, do entendimento da ação de um agente social específico, a Igreja Católica, tendo a especificidade turístico-religiosa como elemento principal das transformações urbanas. Desse modo, parte-se de uma abordagem e contextualização histórico-geográfica dos processos que fomentam a produção e reprodução do espaço urbano de Aparecida. Acredita-se que a particularidade religiosa e a ação da Igreja Católica, reproduzem um espaço urbano singular voltado para profano (a cidade), o comércio turístico-religioso, sobretudo, através dos empreendimentos da Igreja Católica. Para analisarmos essa complexidade que é a produção do espaço urbano em Aparecida, foram feitas pesquisas bibliográficas e uma entrevista com o representante do Santuário Nacional. Dessa forma, este artigo busca compreender essa complexidade que é esse espaço urbano e o papel da Igreja Católica.
\end{abstract}

Palavras-chave: Produção do espaço, Igreja Católica, Aparecida.

Abstract: Its religious tourism status is well known in the country. However, the very production and reproduction process of that urban space, not only currently but since its formation, is due to other aspects, mainly to the actions of several social agents. Therefore, that process derives from such social relations, especially in the context of historical social relations with the Paraíba Valley region, with the city of Guaratinguetá, and specifically with the Catholic Church - and so the religious tourism specificity is the leading aspect for urban changes. Thus, this work is based on a historical geographic approach of the fomenting processes of urban space production and reproduction in Aparecida. It is believed the religious aspect, and Catholic Church interference results in a peculiar urban space revolving around the profane (the city), the regilious tourism market, above all, through the projects of the Catholic Church. To analyze this complexity that is an urban space production in Aparecida, were made Bibliographical research and interview with representative of Nacional Sanctuary. Thus, this article seeks to understand this complexity is that this urban space and the role of the Catholic Church .

Keywords: Space production, Social Agents, Catholic Church, Aparecida. 


\section{Introducão}

A produção do espaço nas cidades tem sido interesse de grande parte das ciências sociais e humanas na busca pela compreensão da formação do espaço urbano e as relações sociais. Essas ciências contribuíram ao trazer para o escopo a interação das relações sociais no processo de produção do espaço e não mais isoladas. Assim, este artigo tem como objetivo geral apresentar o processo de produção do espaço urbano em Aparecida, a partir dessas relações sociais, mais especificamente, o agente social específico, a Igreja Católica.

A cidade de Aparecida surgiu no entorno do culto a imagem de Nossa Senhora da Conceição, mas também das relações sociais e processos econômicos no Vale do Paraíba e de uma relação histórica de pertença com o município de Guaratinguetá. No entanto, Aparecida é um caso singular e sua função religiosa se destaca no processo de produção do espaço urbano, principalmente, sob a ação da Igreja Católica.

O entendimento dessa função turístico-religiosa na produção do espaço é prioritário para a contextualização da história de sua formação, do surgimento do sagrado, da construção da cidade-santuário, da produção capitalista do espaço sagrado e a transformação do espaço do entorno, a própria cidade. Deste modo, o estudo atentou-se a autores que introduzem a especificidade do sagrado e os agentes sociais envolvidos na produção do espaço.

Em primeiro momento o estudo procurou pautar o início, por assim dizer, de uma ação da Igreja Católica no espaço urbano de Aparecida, e as interações com o agente social, o Estado. O segundo momento diz respeito aos empreendimentos desse agente social na produção do espaço urbano, que está muito além do sagrado e da prerrogativa da evangelização. Esse, ao mesmo tempo, fomenta a reprodução dos espaços urbanos por outros agentes sociais. Por último, este estudo apresenta o parecer desse agente social quanto aos empreendimentos e suas ações em Aparecida, etapa esta que foi realizada por meio de entrevista com o representante do Santuário Nacional em exercício.

\section{Apontamentos para compreensão histórica de Aparecida}

A história do município de Aparecida confunde-se com o descobrimento da imagem de Nossa Senhora da Conceição Aparecida. A cidade, outrora povoado e distrito de Aparecida, pertenceu ao município de Guaratinguetá até 1928.

Como subscreve Oliveira (2001, p. 59), "sua [Aparecida] história e dinâmica social sempre acompanharam o desenvolvimento de Guaratinguetá, inclusive pela aproximação das malhas urbanas entre ambos os sítios (conurbação)". Portanto, a investigação desse espaço urbano passa pelo entendimento dessa relação conjunta dos municípios Guaratinguetá-Aparecida e sua integração regional.

Os municípios de Aparecida e Guaratinguetá fazem parte da região conhecida como Vila de Santo Antônio de Guaratinguetá, uma área de ocupação muito antiga, que data de meados do século XVII, iniciada pela exploração das minas de ouro para além da Serra da Mantiqueira, e que destacou-se juntamente com a Vila de Taubaté como uma das principais capitanias do Vale do Paraíba, importância proveniente do ciclo do ouro, da cana-de-açúcar e, posteriormente, do ciclo cafeeiro (HERMMAN, 1986; PASIN, 1983).

Como descreve Moura (2002, p.30), esses ciclos econômicos geraram na Vila de Santo Antônio de Guaratinguetá uma elevação no nível de vida, "e que se reflete em 
modificações na estrutura profissional", além do aumento do povoamento. No entanto, para esse estudo o fator determinante e de interesse que estimulou o aumento do povoamento da Vila, além do ciclo canavieiro, foi a descoberta de uma imagem sacra no rio Paraíba em 1717 (OLIVEIRA, 2001). Os relatos mais aceitos do advento da descoberta dão ênfase a uma peculiaridade, um evento político do período, a passagem do Conde de Assumar pela região para tomar posse da Capitania Independente de São Paulo e Minas do Ouro, em 4 de setembro de 1717 (BARBOSA, 2007).

A mesma prerrogativa sobre o surgimento dos centros religiosos encontramos em Rosendahl (2008, p. 77), que descreve que "os centros religiosos brasileiros como expressão do catolicismo popular originaram-se a partir de diversas manifestações do sagrado, relacionadas, em sua maioria, a fatores socioeconômicos e políticos".

A história contada descreve que, para entreter o ilustre Governador Conde de Assumar em passagem pela região, a câmara da Vila de Santo Antônio de Guaratinguetá providenciou um banquete, para o qual os pescadores locais deveriam capturar os alimentos (BARBOSA, 2007). A tarefa coube aos pescadores João Alves, Domingos Garcia e Felipe Pedroso (BARBOSA, 2007). E assim, reproduzido nas mais variadas bibliografias e no Livro do Tombo da Paróquia de Santo Antônio de Guaratinguetá:

No ano de 1719, pouco mais ou menos, passando por esta Vila para as Minas o Governador delas e de São Paulo, o conde de Assumar Dom Pedro de Almeida, foram notificados pela Câmara os pescadores para apresentarem todo o peixe que pudessem haver para o dito Governador. (MACHADO, 1979, p. 43)

A urbanização e produção do espaço no Vale do Paraíba é tida como uma das mais antigas do Estado de São Paulo, com quatro séculos de desenvolvimento (MULLER, 1969). Esses núcleos urbanos surgiram das vias de circulação originadas pelos ciclos econômicos, a única exceção é o povoado de Aparecida, que advém do achado e da criação da capela para o aporte da imagem de Nossa Senhora Aparecida, sendo que no seu entorno se desenvolveu o povoado (MULLER, 1969). Segundo Machado (1979), a prática era comum, já que se sabe que em todo o período de colonização brasileira os povoados se formaram ao redor de uma capela.

O povoado de Aparecida surgiu, então, no entorno da descoberta, na primeira capela no Porto do Itaguaçu, descrita como "uma capelinha de pau-a-pique, pequena, em lugar barrancoso, sujeito a enchentes, que já não comportava os fiéis que ali acorriam em um número crescente" (FREITAS, 1978, p. 17).

Essa primeira capela consiste no espaço sagrado primário, o espaço da manifestação do sagrado. Como discute Rosendahl (2009, p. 82), a organização espacial nas cidades-santuário acontece de duas formas: o espaço sagrado primário "o locus da hierofania" " e o espaço sagrado secundário, que provém do aumento de peregrinos e devotos, que resulta na hierópolis ${ }^{2}$ na expansão de determinado santuário.

Essa organização espacial também é referenciada por Machado (1979, p. 188), que explica que os devotos reclamavam da dificuldade de acesso e da falta de espaço. Com a intensa demanda que o rito propagou, em virtude do crescente número de peregrinos, fazia-se necessário demolir a primeira capela e construir outra, bem mais espaçosa e em melhor situação. Os romeiros reclamavam do difícil acesso ao local histórico, por ocasião das enchentes do Rio Paraíba do Sul. Escolheu-se então, o novo local - o Morro dos Coqueiros, o espaço secundário que depois se expandirá em uma nova Basílica mais moderna no bairro da Ponte Alta.

Desse espaço sagrado e com a crescente devoção, tem início o próprio processo de produção do espaço, com a construção de uma capela maior e melhor estruturada para 
o acolhimento da imagem na região do Morro dos Coqueiros (1744 e 1745) e das doações de terras nas proximidades com o rito. Freitas (1978, p. 17) relata que

Escolheu para isso o Morro dos Coqueiros, no alto da colina, lugar aprazível, de vista magnifica e iniciou as obras em 1743. Com a ajuda dos devotos, em dinheiro, material e mão-de-obra, concluiu-a dois anos depois, feita de taipa $[\ldots]$

Essa primeira capela (Figura 1) que deu início à ocupação do espaço em Aparecida é exatamente onde se encontra hoje a Basílica Velha ou Igreja Velha. A primeira capela e todo o fomento por trás do simbólico é o momento específico em que a posição da Igreja Católica inicia, de certa forma, sua presença em Aparecida, e de onde exercerá importante função na expansão do urbano e do seu próprio espaço, ao qual denominamos como espaço da Igreja.

Figura 1 - Pintura da Igreja de Nossa Senhora da Aparecida - 1817.

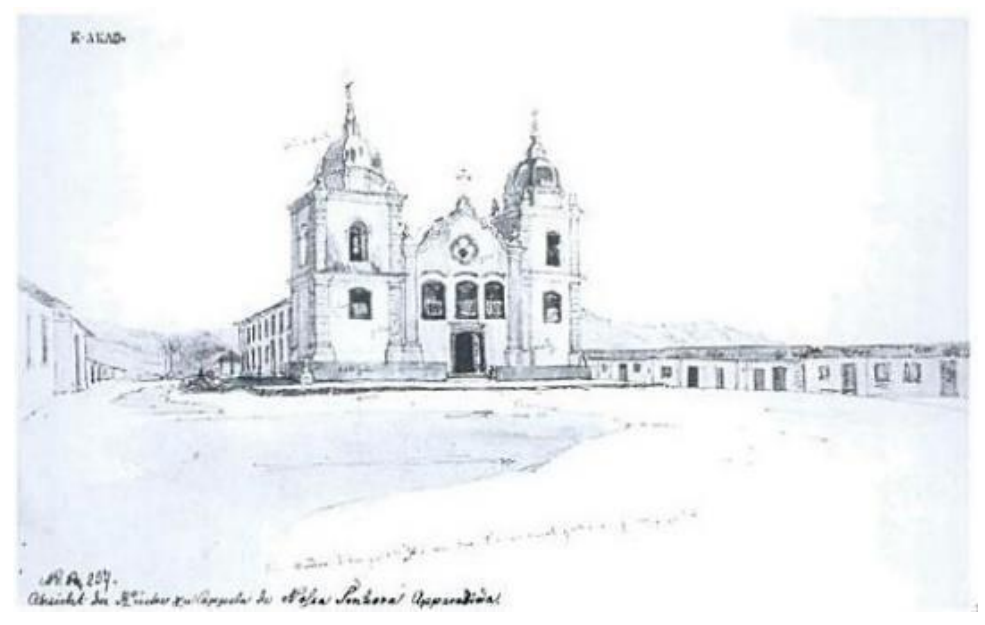

Fonte: MOURA (2002, p. 35). Artista: Thomas Ender.

O papel da Igreja Católica no processo de producão do espaco urbano - o sagrado e o profano

Ao adotar a Igreja Católica como um agente social é importante compreender que sua atuação no espaço não ocorre de forma isolada, já que sua intervenção decorre da associação com os demais agentes sociais. Historicamente, ela mantém relações de relativa interdependência com o Estado.

A Igreja, durante muito tempo, prosperou com essa interação ao ser subsidiada pelos imperadores e reis. Esse vínculo conferia uma relativa tolerância, uma simbiose entre os envolvidos, sobretudo quanto aos desígnios e meios tomados pelos soberanos em infligir atrocidades e em comandar. No Brasil, a interação entre Igreja Católica e Estado - que esteve presente durante a colônia - foi rompida com a criação do Estado laico em 1891, na República Velha. Essa situação permitiu com que outras religiões pudessem ampliar sua influência e competir pelo domínio religioso do território brasileiro, o que culminou com a atuação mais incisiva por parte da Cúria Romana na Romanização do território brasileiro (OLIVEIRA, 2001). 
Esse processo atingiu o Distrito de Aparecida, que ainda pertencia à Vila de Santo Antônio de Guaratinguetá. Lá, a atuação da Igreja na produção do espaço teve início com a Congregação do Santíssimo Redentor, em 1894, cuja função principal era administrativa e de reorganização do santuário para a imagem sacra (OLIVEIRA, 2001). Essa condição seria o primeiro sinal de uma atuação mais preponderante deste agente no espaço e no desenvolvimento de um futuro centro mariano e, por sua vez, na sua comercialização.

Oliveira (2001, p. 60) destaca que

Somente após a implantação da República e a separação administrativa entre Igreja e Estado se estabelecem as condições políticas e simbólicas para a ação ofensiva de demarcação do espaço sagrado em meio a um território profanado pelo Estado laico.

É nesse período de "separação" entre Igreja e Estado que se constitui a formação do espaço sagrado no Distrito de Aparecida, com a construção da primeira igreja voltada para o acolhimento da imagem sacra.

Acreditamos que além dessa compreensão política é fundamental para o entendimento do surgimento dessa cidade a concepção dos termos sagrado e profano e suas relações no processo de produção do espaço. Segundo Eliade (1992), o sagrado é uma revelação, uma manifestação diferentemente do profano que transcende a concepção do homem, é o invisível dentro das categorias espaço-temporais, uma hierofonia diferente do mundo cotidiano, é a manifestação do sagrado em um objeto qualquer.

Para o autor (1992), é a partir do sagrado que há o profano, em uma relação dialética em que compreensão de um envolve a compreensão do outro. Assim, o profano consiste no exterior à manifestação do sagrado.

\begin{abstract}
A experiência profana, ao contrário [do sagrado] mantém a homogeneidade e, portanto, a relatividade do espaço. Já não é possível nenhuma verdadeira orientação, porque o "ponto fixo" já não goza de um estatuto ontológico único; aparece e desaparece segundo as necessidades diárias. A bem dizer, já não há "Mundo", há apenas fragmentos de um universo fragmentado, massa amorfa de uma infinidade de "lugares" mais ou menos neutros onde o homem se move, forçado pelas obrigações de toda existência integrada numa sociedade industrial (ELIADE, 1992, p. 27-28).
\end{abstract}

Deste modo, identifica-se em Aparecida que a imagem sacra é a manifestação do sagrado e que ao mesmo tempo esse objeto originará outros pontos "fixos" e objetos sagrados no urbano, como as igrejas, e, no entorno do sagrado, o contraponto, o espaço profano.

Esse marco na historicidade do povoado concebe, como propõe Eliade (1992, p. 42), o primeiro "centro do mundo", por onde toda a existência do homem religioso se resume ao espaço sagrado, o local para o qual o indivíduo encontra a proximidade com o céu e o distanciamento da profanidade (a terra).

Para Rosendahl (1996, p. 39), "é possível reconhecer o sagrado, não como aspecto da paisagem, mas como elemento de produção do espaço". Dessa forma, tem-se no Distrito de Aparecida (e posteriormente no município) a importância desse aspecto sociocultural na produção e reprodução do espaço.

Com a edificação desse primeiro santuário, tem-se, então, um lugar sagrado e de posição central. Envolto nesse simbolismo, forma-se em seu entorno o espaço profano, o espaço das materializações sociais, a organização espacial do sagrado e do profano. $\mathrm{Ou}$ seja, o próprio espaço urbano de Aparecida. 
A organização espacial das cidades é reflexo das relações vivenciadas no passado que moldaram os espaços do presente. Essas relações são carregadas de representações e símbolos que transformam o espaço, sendo que uma dessas representações simbólicas é a própria bipartição do espaço sagrado e do espaço profano em Aparecida (ROSENDAHL, CORRÊA, 1989).

Para Corrêa (2012, p. 140), os lugares simbólicos:

[...] resultam de complexo processo de criação, interno ou externo, para o qual há várias tensões que envolvem diferentes agentes sociais criadores e usuários de significados. Desse processo, resultam a preservação ou transformação, parcial ou não, dos lugares simbólicos e a ressignificação de seu status político, religioso, étnico ou histórico, que pode ou não incluir sua mercantilização. Nesse caso, é possível falar em lugares simbólicos mercantilizados, cujas paisagens e história foram valorizadas ou plenamente inventadas.

A cidade de Aparecida representa esse lugar simbólico mercantilizado, uma hierópolis, ou cidade-santuário, que reflete crenças e buscas do homem pelo sagrado que é profanado pela produção capitalista desse simbólico. Neste sentido, a Igreja Católica alicerçou sua posição frente a manutenção do sagrado e em sua reprodução no espaço profano, o urbano.

\section{O espaço além do sagrado, os empreendimentos da Igreja Católica e a reproducão do espaco urbano}

Como sintetizado anteriormente, a Igreja Católica como agente social concretiza sua ocupação e influência sobre a localidade com o surgimento do primeiro espaço sagrado, a capela erguida em 26 de julho de 1745, pelo padre José Alves Vilela, pertencente à eclesiástica de Guaratinguetá (MOURA, 2013). Todavia, a atuação oficial deste agente social somente ocorre com a presença administrativa e política da Congregação do Santíssimo Redentor, em 1894 (OLIVEIRA, 2001). Mas não é prioritário para esse artigo remetermos a historicidade deste processo, e sim ao momento que consideramos preponderante na produção do espaço urbano e na solidificação da Igreja Católica como principal agente social em Aparecida.

As primeiras romarias ou peregrinações na região da primeira capela eram apenas devocionais, a área do entorno e tão pouco a igreja estabelecida no Morro dos Coqueiros não forneciam para os devotos condições adequadas para hospedagem. Como descreve Machado (1979, p. 325), os primeiros romeiros subiam as ladeiras da atual rua Monte Carmelo,

onde assistiam à missa e se demoravam rezando; ficavam alguns dias na cidade para descanso e passeios na redondezas, hospedando-se na chácara dos Morais, onde havia casas para os romeiros (devendo ser a precursora da atual função hoteleira da cidade), ou no Chalé da Santa, grupo de chalés construídos para esse fim.

A produção do espaço em Aparecida, do desenvolvimento e da atuação da Igreja Católica envolve acima de tudo, compreender essa dinâmica entre as peregrinações, o objeto sagrado e as ações que o cercam, como o ato de popularização do rito, a partir das materialidades sociais.

Como aponta Reschilian (2005), um marco importante na urbanização do Vale do Paraíba e consequentemente no processo de propagação do rito é o sistema de transporte, 
ou seja, as materialidades sociais. Essa condição de produção do espaço mediante a inserção de um sistema de transportes também é apontada por Oliveira (2001, p. 68), para ele o alcance e aumento da mitogênese ocorre da inauguração do trecho de Aparecida da Estrada de Ferro D. Pedro II (Estrada de Ferro Central do Brasil) em 1877, que permite "as primeiras romarias institucionais em 1900 e demarca a importância dos meios de transporte" no sistema de comunicação e propagação do sagrado.

De fato, o fator fundamental para o posicionamento do culto como identidade nacional e da posição da Igreja Católica frente a essa demanda ocorre em 1931, com a consagração nacional no Distrito Federal (Rio de Janeiro), e assim oficializando o rito religioso com a política cultural.

A crescente propagação do rito e das romarias demonstravam uma necessidade latente de expansão e construção de um novo espaço para o sagrado. Como explica Braga (1987, apud Oliveira, 2001, p. 79), "desde 1926, a necessidade de uma nova igreja era sentida pelos padres e a antiga basílica já estava pequena para o número de fiéis que a ela se dirigia".

A organização espacial da cidade de Aparecida já apresentava os primeiros sinais da incongruência da capital profana em atender à crescente expansão que o culto à Santa desencadeou, como a ausência de infraestrutura no aporte ao agente modelador (devotos); ruas desmanteladas; falta de transporte; energia elétrica e serviços diversos (OLIVEIRA, 2001).

Essa incongruência do espaço urbano no atendimento, na prestação e adequação de serviços ao agente modelador é, então, um elemento chave para o início do processo de surgimento da obra monumental, a Basílica Nova - Santuário Nacional.

A nova casa para a imagem de Nossa Senhora da Conceição Aparecida, dentro do espaço urbano, acentuou ainda mais a condição de dependência do município para com a Igreja Católica, principalmente por que não houve preparo infraestrutural do poder público em adequar a demanda de devotos e de serviços diversos para o contingente.

O local escolhido, no bairro da Ponte Alta, dista aproximadamente dois quilômetros da primeira capela, o que retrata, a princípio, uma preocupação quanto ao distanciamento do espaço sagrado primário, mas também o processo de descentralização do espaço urbano já saturado no entorno da Igreja Velha.

A monumentalidade do Santuário Nacional sinalizava para uma disparidade do município e do rito que se desenvolvia em seus limites. A cidade se tornara limitada em sua forma urbana, insustentável para tal grandiosidade que se instalava. É essa insustentabilidade que fortalece a necessidade de criação de um espaço da Igreja funcional:

\footnotetext{
No início, o contraste justificava-se no simbolismo espiritual de que a padroeira da maior nação católica deveria ser acolhida na maior casa eclesial. Décadas depois, percebeu-se que esta casa seria ainda maior se multiplicasse a funcionalidade de suas dependências, ficando autônoma do povoado que ocupava seu entorno (OLIVEIRA, 2001, p. 80).
}

A construção do templo é, portanto, uma necessidade tanto para Igreja quanto para o município, a fim de separar a balburdia que se instalara com o desenvolvimento do rito religioso. Segundo o representante do Santuário $\mathrm{Nacional}^{3}$, buscava-se aumentar a qualidade da prestação de serviços no entorno até então, ineficientes. Desse modo, "a Igreja começa a administrar a cidade indiretamente, mas não é por que a Igreja quis fazer isto ou por ser um elemento de poder, [mas é] a partir de uma necessidade" ${ }^{4}$ de atender as deficiências da municipalidade no trato com o agente modelador. 
A Igreja busca com essas obras obter "o pleno comando do ir e vir do romeiro e de tudo aquilo que o romeiro precisasse", além de limitar a formação e o desenvolvimento do mercado ambulante nos seus pátios e áreas internas.

É a partir dessa preocupação e da necessidade de agregar funcionalidade ao espaço da Igreja, portanto, que surge o Centro de Apoio ao Romeiro (CAR) (Figura 2).

Figura 2 - Prefeitura Municipal de Aparecida (2015).

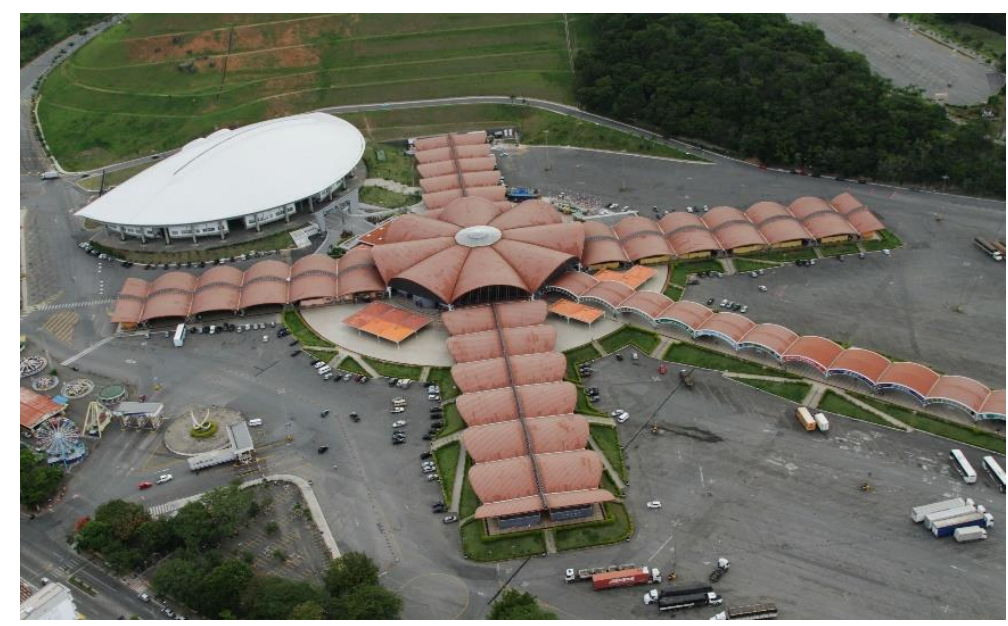

Foto tirada por Luiz Nogueira.

O CAR é um espaço que concentra atividades que, em tese, o peregrino não encontra no espaço do entorno, ou seja, na própria cidade de Aparecida. Esse local de acolhimento, segundo Caravelli (2009), representa uma singularidade das cidadessantuários modernas, uma nova forma de religiosidade e de privatização do espaço sagrado, em que o ato de devoção e de exercer a fé na sociedade moderna tem estado em concordância com o ato individualista do homem moderno.

A religião não deixou de existir, e sim não atua mais como o fundamento estrutural da sociedade. $\mathrm{O}$ mundo moderno não é mais estruturado somente pela lógica do sagrado. Há predomínio de uma razão antropocêntrica, acarretando o duplo processo de pluralização e privatização das crenças religiosas (CARAVELLI, 2009, p. 78).

Nesse novo espaço, então, esse novo romeiro é um turista-religioso que desembarca não apenas para a reflexão e busca de bênçãos do sagrado, mas para a contemplação do espaço mercadoria e de reprodução do capital. Compreende-se que o "novo Santuário" não é apenas um espaço sagrado teofânico, mas um espaço de atrativos diversos, em que a religiosidade permeia os artífices do consumo e da sociedade mundana.

Como descreve Caravelli (2009, p. 78), na sociedade moderna e contemporânea há "uma correspondência entre a religião e o consumo" e com isso há o surgimento de "novas experiências religiosas", que aliam ao sagrado centros de consumo e de vivência.

O Santuário Nacional ${ }^{6}$ compartilha esse pensamento de Caravelli (2009), como pode ser visto da fala do entrevistado sobre os novos romeiros:

Ele [romeiro] quer ter elementos para construir sua própria religiosidade, não se deixa construir sozinho. Isso é uma novidade da pós-modernidade, porque antes você vinha e você recebia, a Igreja te dava, fazia a catequese, a Igreja te formava, hoje em dia não. Hoje a pessoa recebe, analisa, trabalha aquilo e introjeta aquilo que ela julga introjetar. 
As ações da Igreja Católica analisadas a partir das bibliografias estavam restritas, até o presente momento, à criação do espaço sagrado secundário, a Igreja Velha, ao surgimento da Congregação do Santíssimo Redentor, em 1894, e à criação do Santuário Nacional e todo o complexo que o circunscreve. Há, no entanto, nas ações restritas ao espaço da Igreja, uma reprodução do espaço do entorno, comumente chamado de espaço profano, tais como os hotéis, as lojas de comércios diversos e toda a rede que o constitui. Porém, identifica-se uma produção do espaço urbano relacionada diretamente ao surgimento do empreendimento "Cidade do Romeiro" (Figura 3).

Figura 3 - Projeto Cidade do Romeiro.

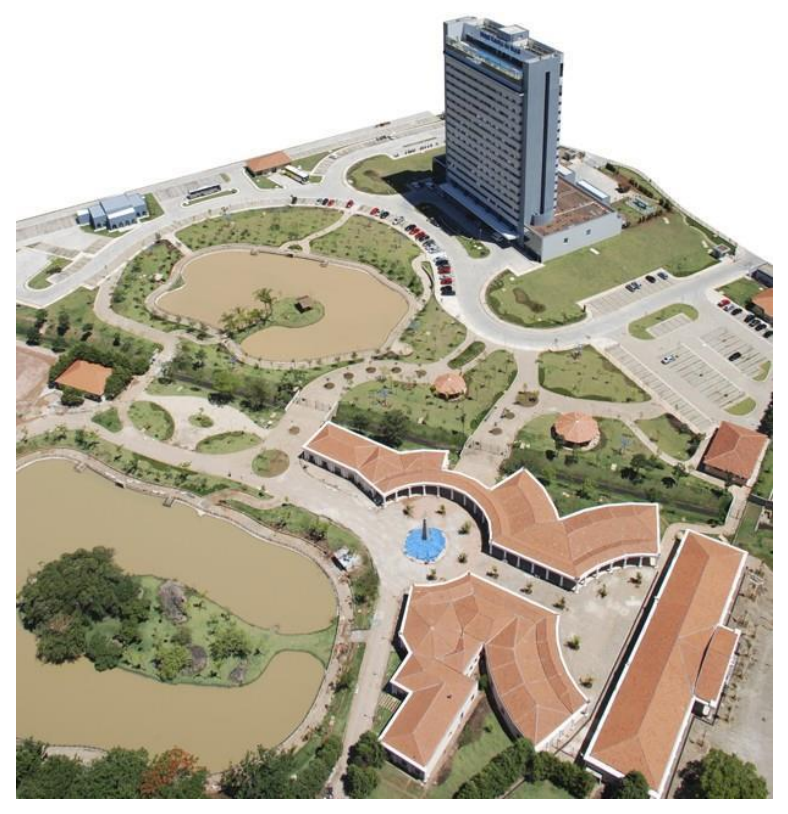

Fonte: Divulgação/Santuário Nacional

A Cidade do Romeiro é uma materialidade no espaço urbano projetada pelo Santuário Nacional para acolhimento dos devotos e como um centro turístico-religioso e comercial. Esse produto turístico, a aproximadamente 700 metros do Santuário, foi inaugurado no dia 15 de dezembro de 2012 e lançado com investimento parcial de 60 milhões de reais provenientes do Banco Nacional de Desenvolvimento Econômico e Social (BNDES).

O empreendimento contará com cinco hotéis, o Hotel Rainha do Brasil, Web Hotel, e outros ainda sem prazo de realização, além de lojas e outros estabelecimentos comerciais.

O complexo comercial demonstra mais um posicionamento da Igreja Católica em um processo de dissociação do espaço do entorno, correspondendo aos anseios desse agente social na desvinculação com a cidade que cresceu em volta do Santuário. Essa conclusão pode ser entendida na explicação retirada da entrevista dos representantes da Igreja Católica ao jornal Estado de São Paulo:

Achamos que seria uma boa oportunidade de melhorar a qualidade do atendimento aos romeiros", diz o padre Luiz Cláudio Alves de Macedo, responsável pela administração do Santuário. Não é pela falta de leitos: são 31 mil disponíveis em Aparecida. "Mas a rede de hotelaria e os serviços da cidade ainda não oferecem conforto suficiente para os peregrinos, afirma o padre ${ }^{7}$. 
Há também uma preocupação da Igreja Católica ao criar esses empreendimentos para atender um público exigente, de demanda elevada, o que se pode concluir pelo padrão dos serviços e pelos preços cobrados nos estabelecimentos da Cidade do Romeiro.

A Igreja tem, ao longo do surgimento de Aparecida, demarcado sua presença no espaço das mais diversas formas, seja na instituição do rito sagrado e nas construções, como no presente, seja no estabelecimento de novos espaços comerciais. Dessa ação na historicidade do município, observa-se que, a partir do desenvolvimento de outros produtos turísticos ligados à exploração do sagrado, a Igreja Católica tem expandido seu alcance e sua inserção direta no processo de produção e, de forma indireta, na reprodução do espaço urbano, além de, concomitantemente, aumentar a relação de dependência da municipalidade para com esse agente social.

Os pontos-turísticos - o Morro do Cruzeiro e o Teleférico - são outros exemplos da inserção direta da Igreja Católica na produção e na reprodução do espaço urbano. $\mathrm{O}$ Morro do Cruzeiro, antes de ser identificado como esse ponto turístico-religioso na cidade de Aparecida, era almejado pelos redentoristas como um importante ponto para a construção do novo Santuário, em meados de 1939 (BRUSTOLONI, 1980). Na tentativa de solidificar essa possibilidade e evitar a expansão das habitações ao redor da localidade, dom José autorizou a compra de duas fazendas (Vieira e do Nogueira) na área do Morro do Cruzeiro, perfazendo 100 alqueires (BRUSTOLONI, 1980). Mas a baixa qualidade do terreno para edificações não permitiu a continuidade da empreitada e outra área precisou ser escolhida para a construção da Basílica Nacional, no caso, o Morro das Pitas (BRUSTOLONI, 1980).

Compreende-se, assim, que o Morro do Cruzeiro fazia parte das pretensões da Igreja Católica para a construção do Santuário e que havia uma preocupação com um distanciamento das habitações em constante expansão no município. No entanto, sua incorporação nos moldes de ponto-turístico tem início somente em 1948, quando foram inauguradas as capelinhas para realização da tradicional caminhada da Via-Sacra (BRUSTOLONI, 1980). Todavia, a localização em uma área ainda incipiente de serviços públicos e de baixo desenvolvimento infraestrutural relegou o projeto ao abandono e, por consequência, não houve qualquer estruturação para a prática do turismo-religioso. Essa condição se altera no ano 2000, com a predisposição da Igreja em estruturar o espaço para o funcionamento das práticas religiosas (BRUSTOLONI, 1980).

O Morro do Cruzeiro torna-se, então, mais um elemento físico da Igreja Católica, um empreendimento que fomenta em seu entorno no surgimento e a expansão de uma área comercial (Figura 4) e na reprodução do espaço urbano. 
Figura 4 - Entrada Morro do Cruzeiro.

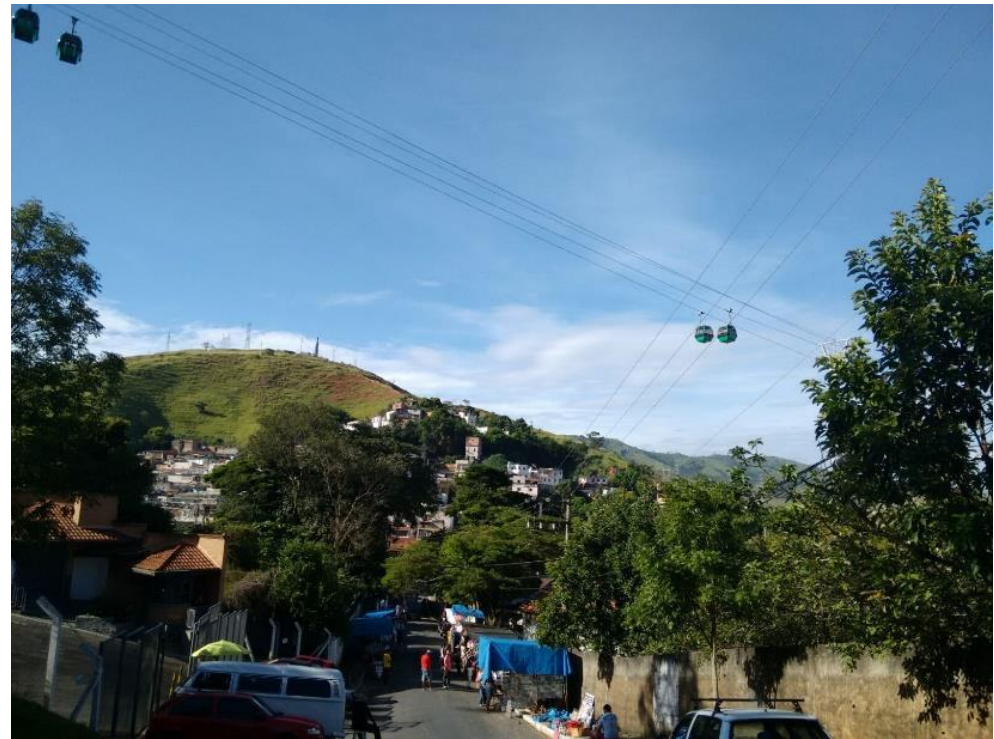

Foto: Ivo Francisco Barbosa, 28/02/2016.

A alteração mais recente no espaço urbano de Aparecida é um exemplo desses novos empreendimentos, o teleférico (Figura 5), que interliga o Santuário Nacional ao Morro do Cruzeiro no bairro Santa Luzia. Um projeto da empresa Bontur S/A, foi inaugurado oficialmente em 25 de junho de 2014 e custou aproximadamente 19 milhões de reais aos cofres da Igreja.

Para o administrador do Santuário, o padre Macedo,

O Bondinho Aéreo vai ao encontro da demanda do público que visita Aparecida, com uma crescente exigência dos serviços oferecidos. O Santuário tem buscado atender essas novas exigências e, ao mesmo tempo, estimular iniciativas na cidade ${ }^{8}$.

De fato, essas materializações no espaço urbano de Aparecida proporcionam uma remodelação e, de certo modo, uma valorização do entorno, até então carente de atrativos ligados ao turismo-religioso em sua forma mais estruturada. Para o representante da Igreja, esse empreendimento trará benefícios à cidade, pois

Temos muito, ainda, aquele turista de um dia, que cumpre suas obrigações religiosas e volta, imediatamente, para sua cidade de origem. Acreditamos que o bondinho aéreo será mais uma possibilidade para que aqueles que vêm a Aparecida tenham motivos para permanecer na cidade ${ }^{9}$.

\section{Segundo o representante continua e explica que}

A medida que Aparecida for criando possibilidades para fazer com que o turista permaneça mais tempo aqui, toda a cidade irá se beneficiar. Então o bondinho também é um alerta para a própria cidade, para que a cidade vá criando alternativas de permanência para que a pessoa venha e não fique somente naquela, naquele momento religioso $[\ldots]^{10}$.

As declarações da Igreja Católica na construção desse e de outros empreendimentos no espaço urbano em Aparecida têm por critério a especialização do 
turismo-religioso, ao adicionar novas demandas para esse novo devoto e uma prerrogativa de fixar esse turista por maior tempo na cidade. Para o representante,

Tudo isso que nós fomos ocupando como espaço e tudo aquilo que foi sendo aparelhado neste espaço é em vista disto 'plantar uma semente do evangelho no coração daqueles que daqui se aproximam, nunca foi para exercer um poder era para responder uma necessidade do romeiro e a uma missão que é nossa evangelizar ${ }^{11}$.

Não se deve desconsiderar essa função da Igreja, mas, a partir de uma análise mais intrínseca, percebemos que esse agente social é muito importante como modelador do espaço urbano de Aparecida, principalmente ao atuar em conjunto com o poder público na alteração e na aprovação de projetos de lei para fundamentação dos próprios empreendimentos, porém essa é não é a discussão $a$ priori.

\section{Consideracões Finais}

Neste município, a Igreja Católica é um agente social capitalista que é simbolicamente ocultado por suas benesses de cunho social e de evangelização. Como agente, busca fundamentalmente se posicionar como uma instituição independente da municipalidade e de diálogo restrito ao desenvolvimento e expansão do turismo-religioso, sem qualquer apreço para com os processos inerentes de suas ações, como as mazelas provindas da privatização do sagrado e da produção e reprodução do espaço.

Por mais que a Igreja atue visando o lucro do espaço sagrado e a já referida interdependência do município, para tal objetivo ela necessita dos demais agentes sociais, sobretudo do Estado, que, como salientou-se neste artigo, sempre esteve presente em uma relação amistosa com o Estado (nas diversas esferas administrativas) na estruturação desse projeto de cidade-santuário, na consolidação do rito, de símbolo nacional, assim, ambos foram e ainda são os agentes sociais proeminentes na formação desse espaço.

Evidentemente, não podemos deixar de creditar ao romeiro o significativo papel na produção do espaço urbano, uma vez que toda a estrutura espacial turístico-religiosa existe para acolhê-lo, mas a percepção do imenso papel da Igreja Católica nesse processo não deve ser relegada a apenas evangelização e o caráter simbólico e sagrado do culto, há outras vertentes e sempre devem ser apresentadas. Todavia, esse artigo não apresenta uma resposta definitiva e tão pouco verdades absolutas, temos no processo de produção do espaço urbano intensas relações sociais atuantes e outras não retratadas que podem corroborar para novas interpretações, e não desconsideramos essa possibilidade. 


\section{Notas}

1 - Este termo é cômodo, pois não implica nenhuma precisão suplementar: exprime apenas o que está implicado no seu conteúdo etimológico, a saber, que algo de sagrado se nos revela" [grifo do autor] (ELIADE, 1992, p. 17).

2 - Refere-se às cidades que possuem uma ordem espiritual predominante e marcadas pela prática religiosa da peregrinação ou romaria ao lugar sagrado. Pelo simbolismo religioso que esses locais possuem e pelo caráter sagrado atribuído ao espaço, podemos chamar esses locais de hierópolis ou cidades-santuários" (ROSENDAHL, 1996, p. 82).

3 - Entrevista realizada com representante do Santuário Nacional, no dia 2 de fevereiro de 2016.

4 - Ibidem

5 - Ibidem

6 - Entrevista realizada no dia 2 de fevereiro de 2016.

7 - Disponível em: <http://www1.folha.uol.com.br/poder/2014/06/1473249-doleiro-e-socio-de-hotel-emaparecida.shtml>. Acesso em: 21 jan. 2016.

8 - Disponível em: <http://www.a12.com/santuario-nacional/noticias/detalhes/bondinhos-aereos-coloremo-ceu-de-aparecida>. Acesso em: 30 nov. 2015.

9 - Ibidem

10 - Ibidem

11 - Entrevista realizada com representante do Santuário Nacional, no dia 2 de fevereiro de 2016.

\section{$\underline{\text { Referências Bibliográficas }}$}

BARBOSA, B. L. Nossas Origens: Três séculos de História de Aparecida-SP. Edição do autor, Aparecida - SP, 2007.

BRAGA, J.A. Diretrizes para expansão urbana de Guaratinguetá - Aparecida. TGI da FAU - USP, 1987.

BRUSTOLONI, J. Construção da Nova Basílica: Documentário e Notícias (19551988). Aparecida, Mimeo, 1980.

25 anos de construção da Basílica Nova. Revista Ecos Marianos. Aparecida. Ed. Santuário, 1982.

CARAVElli, H. G. Turismo religioso no Caminho da Fé. Revista eletrônica de turismo cultural (USP), v. 3, p. 75-94, 2009.

CORRÊA, R. L. O Espaço Urbano. 3. ed. São Paulo: Ed. Ática, 1989. Espaço e Simbolismo. In: CASTRO, I. E; GOMES, P. C. da C.; CORREAA, R.

L.(Org) Olhares Geográficos: modos de ver e viver o espaço. Rio de Janeiro. Bertrand Brasil, 2012.

ELIADE, M. O sagrado e o profano. Tradução Rogério Fernandes. São Paulo: Martins Fontes, 1992.

FREITAS, O. C. Aparecida, capital mariana do Brasil. Aparecida: Ed. Santuário, 1978. 
HERRMANN, L. Evolução da Estrutura Social de Guaratinguetá num Período de Trezentos Anos. São Paulo: Instituto de Pesquisas Econômicas/USP, 1986.

MACHADO, Pe. Aparecida na história e na literatura, Congresso da Padroeira, [S.I.:s.n.], 1979.

MOURA, C. E. de. Vida cotidiana em São Paulo no século XIX. São Paulo: Edusp, 2013. 2002.

Visconde de Guaratinguetá: um fazendeiro de café. São Paulo: Studio Nobel,

MÜller, N. L. O fato urbano na Bacia do Rio Paraíba do Sul - São Paulo. Rio de Janeiro, IBGE, 1969.

OLIVEIRA, C. D. M. de. Basílica de Aparecida: Um templo para a cidade-mãe. $1^{\mathrm{a}}$. ed. v. 1. São Paulo: Olho D'água, 2001.

PASIN, J. L. Guaratinguetá: tempo e memória. São Paulo: Ed. Rk, 1983.

RESCHILIAN, P.R. O Vale do Paraíba no contexto da urbanização brasileira e a questão do planejamento regional. Revista de Ciências Humanas, Taubaté, v.11, n.1, p. 25-32, 2005 .

ROSENDAHL, Z. Espaço e religião: uma abordagem geográfica. 2. ed. Rio de Janeiro: UERJ, NEPEC, 1996.

. Hierópolis: O sagrado e o urbano. 2. ed. Rio de Janeiro: Ed. UERJ, 2009.

O sagrado e o urbano: gênese e função das cidades. Revista Espaço e Cultura (UERJ), v. 1, p. 67 - 79, out. 2008. 